\title{
The Information Economy
}

\author{
Yi-Cheng Zhang
}

\begin{abstract}
In this chapter we outline a novel theory of the consumer market, in which information plays the key role. Consumers know only part of the available business offers and cannot ascertain the quality of the products they desire and businesses have even less knowledge of what consumers desire. In the market consumers and businesses must find a match with severely deficient information. Instead of optimisation under the constraints, our theory focuses on how the information constraints can be gradually reduced. We show that upon constraintreduction we do not come closer to the full information limit typically portrayed in mainstream economics; rather both consumer wants and business offers expand with concomitant new information deficiencies. Therefore the consumer market is always in non-equilibrium and information will always be deficient. We argue that in the dynamic pursuit to reduce information constraints wealth is created and this is the main driving force that powers economic growth.
\end{abstract}

\section{Information as Bottleneck for Economic Transactions}

On historical accounts, both consumer wants ${ }^{1}$ and businesses offers expand, and this powers economic growth. Consumers and businesses seek each other in the market, either on their own or are helped by various third parties to find better matching. Whereas mainstream economics bypasses the information problem in its supplydemand law, ${ }^{2}$ our theory will focus on how consumers and businesses find each other, and how they tackle the information deficiency problem. It will be shown that when more wants and offers are found and matched, still more will be created.

\footnotetext{
${ }^{1}$ In economics consumer wants are are needs or desires that can be satisfied by the consumption of business offers including goods, commodities, services, and leisure activities.

${ }^{2}$ Notable exceptions can be found in George Akerlof's [1] work on information asymmetry, and Joseph Stiglitz's [9] work on information imperfections.

Y.-C. Zhang ( $ه)$

Department of Physics, Fribourg University, Chemin du Musée 3, CH-1700 Fribourg, Switzerland e-mail: yi-cheng.zhang@unifr.ch
} 
As consumers become overwhelmed by the ever more complex world around them it is unrealistic to expect them to increase their information by even more diligence. Significant improvement actually comes from information institutions that enable individual consumers to be better informed. As discussed below, the most effective information institutions can empower consumers by collecting and organising scattered information that isolated consumers already possess, and can achieve information improvement by sharing and channeling information to the right person in the right context.

The new theory goes beyond the mainstream supply-demand law by considering a cognitive gray area. If consumers become better informed, more of their potential wants and the offers of business can be revealed and matched. Our postulate is that, besides the actual transactions, there must be an inexhaustible pool of potential wants and offers that can be gradually revealed and satisfied as information continuously improves.

Our main thesis is that information improvement will power economic growth without limit over time. The enhanced transactions in general will benefit both consumers and businesses, and we can speak of a magic pie of wealth that would be created as if out of the thin air. The concept of a 'magic pie' implies that economic transactions should not be zero-sum-games, and economic problems should not be treated as optimisation under constraints.

\section{The Gray Cognitive Zone}

The focus is now on defining the gray cognitive zone. First we note that information is very unevenly distributed among people, with everyone knowing some things better than other people. A single individual can also have their own personal gray zone, since personal knowledge can be both explicit and implicit and the latter far outweighs the former.

It is not surprising that businesses won't share information fully with consumers and present only a selective view of their products. Among consumers, the available but unevenly distributed knowledge is an inexhaustible resource for their information improvement. When you and I know something well, sharing it is an obvious way to enhance our information coverage. This will be called the Information Division of Labor (IDOL). It can be identified as the main mechanism to empower consumers to be better informed.

There are various reasons why consumers share information among themselves. Firstly they have idiosyncratic motives beyond pure economic calculation-people volunteering cooperation and giving each other tips can be motivated by noneconomic incentives, and yet the people power of IDOL can have huge economic consequences. Secondly the harder consumers scrutinise businesses, the more businesses can improve their offers. In fact it is much easier for businesses to expand the variety and quality of their offers than it is for consumers to change their needs or wants, an asymmetry discussed in details below. Therefore while the interests of 
businesses and consumers are at best partially aligned, consumers see themselves more as fellow tastemates than competitors.

Businesses have hidden information that they may never expose to the outside world, but the effects can manifest nonetheless. Each firm has its own resourcefulness known only to itself, but upon external selection pressure, it may tap into its hidden depth to make its offers more competitive in quality and/or price. Such depth is uneven across businesses, with more innovative and efficient firms better able to survive the competition and dominate.

The second type of cognitive gray zone is implicit knowledge within a single person, which is particularly relevant for expanding consumer wants. People know much more about their desires than they can explicitly articulate. Polany [7] studied implicit knowledge more than half century ago, and many marketing business models actually deal with implicit knowledge using a variety of refined tools. Implicit knowledge is by definition the knowledge you have but cannot easily recall. Although we cannot explicitly recall all our own preferences, what is implicit may become explicit on suitable stimulus and contexts. In fact many marketing strategies aim to convert selectively our implicit needs into commercial transactions.

\section{Information Institutions}

Individual consumers cannot cope well with ever more numerous and complex business offers; they are hard pressed to compare products and determine their quality and suitability. In fact there are many information institutions that we shall call matchmakers who help consumers and/or businesses to find suitable matches. IDOL is an important mechanism that enables consumers to be better informed, but it is only when combined with matchmakers that IDOL can realise its full potential. Take tripadvisor.com as example. Its evaluations of hotels and restaurants are by consumers themselves, but the matchmaker's role is vital in connecting millions of travellers to these evaluators as if they were the quality inspectors from a powerful quality control agency.

Many more matchmakers empower consumers. Online auctions site like eBay lets buyers and sellers rate each other, and their reputation systems keep people relatively honest and trusting when they buy things sight unseen. Amazon lets its customers rate books and countless other products, and the experience and expertise of a small minority of insiders can enlighten millions consumers. Information institutions can apply the latest advances in big data science to recommend relevant items to consumers by figuring out the implications of networks implicit in the data. In fact online matchmakers will be able to leverage IDOL, reputation, and recommendation to empower consumers much further in the future.

Matchmaking institutions play a central role in modern markets, often one that is not conspicuous. We find most products and services on our own, or so it may seem. There are many institutions that enhance consumer's search and evaluation capabilities, while helping businesses to target advertisements. Matchmaking institutions 
enjoy an obvious advantage: a given product will be repeatedly scrutinised many times by many different consumers, allowing a potential customer to benefit from this rich information by studying only it once. Therefore matchmaking institutions can be very efficient in overcoming the information deficiency problem. However, as will be seen, they are not necessarily neutral arbiters sitting between consumers and businesses; often they choose to help one side more than the other, and they have much leeway in doing so. For a better understanding the dilemma of who to favour in providing help, we look to a well known mathematical model for insight.

\section{Matching with Partial Information, SMP Revisited}

In this section we focus on an academic research program that underlies much of the current and future business models of matching consumers' wants to businesses' offers.

Gale and Shapley [3] first found a solution to the so-called Stable Marriage Problem (SMP). Let us first consider their original model and then extend it to matching consumers and businesses. Suppose there are $N$ men and $N$ women wishing to marry a member of the opposite sex, that each knows all the $N$ members of the other side and ranks them, and each person's ranking list is independently distributed. Let each man propose to the women one by one from the top of his preference list downward, and let each woman evaluate the proposals and keep temporary the best candidate on her preference list. The rounds continue until each is matched to a single partner. The final matching can be shown to be stable, in the Pareto sense.

We can define a happiness parameter to measure the quality of the matching. If your mate is at the top of your preference list, your happiness is maximal; if your mate is ranked at the bottom of your list, your happiness is zero. Though the GaleShapley solution is proven to be stable, the collective happiness is far from being maximised. In fact if both men and women take initiatives to propose to each other in a symmetrical fashion, the combined collective happiness can be much higher than that of the GS algorithm of men-initiatives alone [6]. Moreover, if a matchmaker arranges the matching it can be shown that the best combined happiness can be obtained, beyond the capabilities of those directly involved.

The unrealistic assumption of perfect information in the SMP, that each man and woman knows all the members of the other side, can be relaxed. Suppose each person knows just a partial list of the available candidates. The Pareto stability criterion will be violated for some pairs, but satisfactory solutions (in the sense of Herbert Simon) can be achieved with a higher combined collective happiness than the GS stable solution. Recent research shows that as partial information is improved, with each person knowing more candidates, the collective benefits increase [10].

To apply this to the problem of matching consumer wants versus business offers requires some important modifications to the standard SMP model [4]. Firstly we 
note that the supply-demand relationship is not necessarily one-to-one, it is more often one-to-many, i.e. one firm produces for many consumers. Secondly consumers face a severe information deficiency problem [1] and both consumers and businesses have very limited knowledge of the other side. Thirdly, unlike in SMP where both sides have fixed attributes and wish lists, in the economy consumer wants and business offers can change and expand endlessly. Therefore we must deal with a dynamic matching problem.

There are many mutually beneficial solutions to matching problems, but the benefits are not necessarily split equally between the two sides. Due to the severe knowledge limitations knowledge of both, consumers and businesses rely heavily on third parties for their information requirements. This gives matchmakers considerable leeway in deciding which side to help most. The prevailing matchmaking business models favour businesses. This is because businesses are more analytic and more willing to pay the matchmakers for their information services. Consumers on the other hand prefer free information services, for example many internet companies such as search engines give information services for free to consumers and target them with advertisements on behalf of their business sponsors.

The reasons for businesses being more willing to pay matchmakers can be traced to the consumer theory of Tibor Scitovsky [8]. He suggests that businesses are specialists while consumers are generalists, and that specialists are by definition more analytic and can evaluate the difference that a matchmaker can make. Moreover, consumers are much more numerous than businesses and it is easier for matchmakers to establish contracts with businesses [2].

There is one major problem with the asymmetrical service by the information matchmakers. Both consumer wants and business offers can expand without limit but the latter is significantly easier. Helping one side means exerting a higher selection pressure on the other side. The problem is that consumer wants are relatively less expandable than the business offers. Surprisingly, the prevailing matchmaking business models are actually at odds with long term trends because of the following asymmetry.

\section{The Fundamental Asymmetry}

Above it was emphasised that our theory differs in a crucial way from mainstream economics. Instead of maximising under fixed constraints, we consider changeable constraints. As has been argued, consumer wants and business offers are constraints that can be expanded. In this section we posit that while constraints on both sides can be shifted, it is much easier to shift the constraints of the business side. We call this the fundamental asymmetry that underlies any dynamic theory of markets.

When pressed, businesses have more opportunities to revise their offers than consumers can expand their wants, even though in principle the latter are also boundless on historical accounts. The asymmetry manifests itself in the ease, scope, and speed of constraint-shifting. 
Consider how each side can shift the constraints. Upon increased consumer selection pressure aided by information institutions, businesses are forced to revise their offers. In the short term they will cut prices and/or improve quality of their products. In the long term they must find new and more efficient ways to produce their current products, as well as look for new products anticipating consumer demand, thereby diversifying their offers. Here, direct pressure actually comes from the competition, which is only effective when empowered consumers exercise enough discerning capabilities. Therefore the ultimate driving force that obliges businesses to dig into their reserves comes from consumers.

Consider see how consumers' wants can be expanded. Since each person's income is limited (though people's income may increase with expanding business offers, in a growing economy both sides expand commensurately), his or her wants can expand slowly. There is also the factor that the price of consumer products typically drops between their inception and maturity. Hence even with a fixed budget a consumer's wants may change.

Businesses try hard to obtain consumer intelligence but they achieve only limited results. The difficulties stem from the following facts. While businesses and their products are public information, consumers' preferences are private, so businesses and their marketing agencies can only get a glimpse on what consumers really desire. Secondly consumers' wants may be implicit or hidden, i.e. even when they are willing to express them, they can only articulate a tiny fraction of their potential wants. Thirdly, businesses don't have sufficient incentive to know individual consumers as their wants are seldom or never repeated. Hence once a want is met it is saturated and it is of no further interest to the vendor. In other words it's much easier to know a business offer that is relatively stable than to know a consumer's needs which may recur infrequently, if at all.

Therefore businesses will be content with superficial data on consumers, such as gender, age, etc., even though such aggregate data are far from drawing the full picture of the individual, since they allow businesses to target a large group from which some individuals will turn out to be buyers. The fundamental asymmetry manifests in another aspect, the tolerance of substitutability. If a consumer specifically needs a blouse, you cannot just give her a hat instead. But instead of one particular consumer, any buyer replacing her will be just as good to the vendor.

Since businesses can more easily expand their offers than consumers can expand their wants, and the increased offers by definition are matched-businesses cannot unilaterally increase offers without commensurate wants. Therefore the asymmetry translates into differences in selection pressures on the each sides. In other words consumers should be assisted whereas businesses should be subject to strong selection scrutiny.

According to the fundamental asymmetry between consumer wants and business offers, the latter have a much larger scope to expand than the former. Since each side faces selection pressure by the other side, the asymmetry results in a long term trend that businesses cede more easily than consumers. The prevailing matchmaking business models helping businesses to put selection pressure on consumers seem to 
be glaringly at odds with this epic trend. However, elsewhere [11, 12] we show in detail that many new emergent business models do go with the trend.

From an optimal matching point of view a matchmaker should enable the maximal combined benefits of the two sides. But there are both short term and long term reasons they don't. The short term reason is that one side is more willing to pay, but it is the wrong side in view of the epic trend. The long term reason is that matchmakers should not merely aim at the current maximal combined benefits, as the other side can more easily expand. Hence they should align with one side (consumers) and exert strong discerning pressure on the other (businesses). Therefore matchmakers' short term profits and long term prospects are in head-on conflict: the former would make them align with the one side and the latter with the other.

The fundamental asymmetry not only is relevant for business models but also determines the long term trend of economic evolution. In the short term a business or its marketing institutions may choose to use clever marketing tools to squeeze consumers for profit because this is easiest to do, but the fundamental asymmetry deems that businesses have much greater room to expand their offers than consumer have to expand their wants. The more innovative entrepreneurs will be encouraged to align their vision and business models with the prevailing trend, and will dig deeper into their resourcefulness. In the long run whoever is going with the trend will reap sustainable rewards and whoever going against the trend may get short term profits but have less chance of long term prosperity.

\section{Diversification}

Our thesis is that information can be always improved and that this in turn can power economic growth by expanding both offers and wants. The next question is that what the expanding economy looks like. We argue below that upon information improvement, not only are there more transactions, but also products tend to diversify.

The following reasons favour product diversification. The first is that if consumers have higher information capabilities for choosing and determining businesses' offers, they have a higher chance of finding suitable products for their personal tastes. We postulate that people have a native predisposition of individual preferences that are far more diversified than suggested by past transaction statistics. With the increasing discerning power consumers reveal more diversified wants. Their information capabilities are regarded as the bottleneck towards full diversification, and luckily the bottleneck is being gradually reduced. This doesn't imply one day we may have perfect information, rather the improvement of information capabilities will herald new business offers with concomitant new bottlenecks. In short, even though consumers will forever have information deficiency, products will not only evolve from the old to new, but also from a few to many. 
Businesses also have incentives to diversify their products. This may sound less obvious since mass production is far more efficient than personalisation. The direct cause is that with improved consumer information capabilities, competition becomes more effective. Heightened competition obliges businesses to go to new production frontiers where competition will be less severe. Not all businesses embrace diversification. Those that are efficient but risk-averse will look for the most popular products to fight the competition head on. More innovative businesses try to avoid crowded product spaces whenever they can, and take calculated risks in new fringe areas.

What trends do the diversifying products represent? When the economy is in a depressed state, such as a deep recession or after a world war, consumers' wants are limited to merely surviving. In general, when the economy is more prosperous, consumers' other non-essential needs can be viable. We can speak of lower wants versus higher wants. Lower wants are related to survival whereas higher wants can be hobbies, sports, entertainment, pastimes - a list that goes on without end. The higher wants tend to be (1) more personal, (2) more numerous, and (3) more implicit than explicit. These three characteristics make them difficult for businesses to detect. Since higher wants tend to differ from person to person, unlike survival needs such as food and shelter, it's harder to discover who wants what. Because they are inhomogeneous across the population, the aggregate number of higher wants is bound to be more numerous. Any single person will have an unlimited number of higher wants, i.e. those non-essential needs hidden in our gray cognitive zone that may be activated by the right stimulus in the right context.

The selective awakening of our implicit wants by marketing tools is the focus of business models in the current information economy. Abraham Maslow, the late American psychologist, first introduced the concept of a hierarchy of human needs [5]. We closely follow his definition in spirit but limit ourselves to commercial wants which are only a fraction of Maslow's higher human needs. Maslow suggested a pyramid to represent hierarchical needs, with the higher needs on the summit of the pyramid. To represent the much larger number of the higher wants versus that of the lower wants, we instead use an inverse pyramid for hierarchical wants. Moreover, the top is open ended as more can be added without limit (Fig. 1).

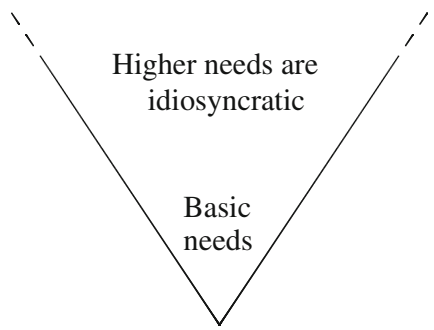

Fig. 1 Hierarchical wants represented by an inverse pyramid with an open expandable top. Lower wants are fewer and better known; higher wants are much more, personal. From the cognitive point of view determining the higher wants is a greater challenge 
We expect the economy to grow by an endless process of matching consumers' increasing higher wants to business offers, followed by uncovering more implicit wants to be satisfied by new business offers, and so on.

\section{Conclusion: The Non-equilibrium Paradigm}

Mainstream economics is essentially a static theory that treats economic problems as optimisation under constraints. In this essay we have outlined a new theory that deals with the gray cognitive zone and focuses on information improvement therein. Information improvement not only reduces the current bottlenecks and thereby increases transaction volumes, but also helps discover new consumer wants and business offers. Our new theory follows throughout this line of argument by proposing a new paradigm in which allocation and creation cannot be separated.

The neoclassical paradigm of allocation underlies mainstream economics. The new paradigm postulates that any allocative acts will move the constraints, creating the new opportunities and risks. As a consequence of the new paradigm we cannot pretend to solve any particular problems without paying attention to changing constraints, so that optimisation is in principle not possible. What will follow is a genuinely dynamic theory where there is no fixed goal to be attained, and temporarily perceived goals will be shifted by current processes. While this conclusion may sound frustrating for theorists versed in the hard science tools for solving optimisation problems, it offers the evolutionary prospective that there is no pre-determined target towards which our economy will converge. There is still a lot we can do and should do, as the future is not completely unknown. Any progress towards conquering the gray cognitive zone will not eliminate or even reduce it, but push it further into newer frontiers. But the effort will not be in vain, as information improvement is the main driving force for an expanding economy. Our theory provides a detailed account how this general statement actually bears out.

Open Access This chapter is distributed under the terms of the Creative Commons Attribution 4.0 International License (http://creativecommons.org/licenses/by/4.0/), which permits use, duplication, adaptation, distribution and reproduction in any medium or format, as long as you give appropriate credit to the original author(s) and the source, provide a link to the Creative Commons license and indicate if changes were made.

The images or other third party material in this chapter are included in the work's Creative Commons license, unless indicated otherwise in the credit line; if such material is not included in the work's Creative Commons license and the respective action is not permitted by statutory regulation, users will need to obtain permission from the license holder to duplicate, adapt or reproduce the material. 


\section{References}

1. Akerlof, G.A.: The market for 'Lemons': quality uncertainty and the market mechanism. Quart. J. Econ. (The MIT Press) 84(3), 488-500 (1970)

2. Coase, R.H.: The problem of social cost. J. Law Econ. 3, 1-44 (1960). http://www.law. uchicago.edu/files/file/coase.pdf

3. Gale, D., Shapley, L.S.: College admissions and the stability of marriage. Am. Math. Mon. 69, 9-14 (1962)

4. Lü, L., Medo, M., Zhang, Y-C.: The role of a matchmaker in buyer-vendor interactions. Eur. Phys. J. B 71, 565-571 (2009)

5. Maslow, A.H., A theory of human motivation. Psychol. Rev. 50, 370-396 (1943)

6. Omero, M.J. , Dzierzawa, M., Marsili, M., Zhang, Y-C., Scaling behavior in the stable marriage problem. J. Phys. I France 7(12), 1723 (1997)

7. Polanyi, M.: The Tacit Dimension. University of Chicago Press, London, Routledge (1966). 2009 reprint

8. Scitovsky, T.: Economic Theory and reality. Edward Elgar, Cheltanham (1995)

9. Stiglitz, J.E., Information and the change in paradigm in economics. Noble Prize Lecture, December 8 (2001). http://www.nobelprize.org/nobel_prizes/economic-sciences/laureates/ 2001/stiglitz-lecture.pdf

10. Zhang, Y-C.: Happier world with more information. Physica A 299, 104-120 (2001)

11. Zhang, Y-C.: Broader scopes of the reflexivity principle in the economy. J. Econ. Methodol. 20(4), 446-453 (2013). http://www.tandfonline.com/doi/full/10.1080/1350178X.2013.865360

12. Zhang, Y-C.: The Structure of Information Economy (2017, to appear) 